\title{
In vitro shoot Proliferation from Nodal Explants of Aegiceras corniculatum L. (Blanco.)
}

\author{
Rajneesh Kumar ${ }^{1 *}$, Animesh Sinha ${ }^{1}$, Pradip Kumar Sarkar ${ }^{2}$ and Jai Kumar ${ }^{3}$ \\ ${ }^{1}$ Genetics \& Tree Improvement Division, Institute of Forest Productivity \\ Lalgutwa, Ranchi, Jharkhand - 835303 \\ ${ }^{2}$ ICAR-Research Complex for Eastern Region, Farming System Research Centre for Hill and \\ Plateau Region, Plandu, Ranchi, Jharkhand - 834010 \\ ${ }^{3}$ Department of Forestry, Birsa Agricultural University, Kanke Road, \\ Ranchi, Jharkhand - 834006, India \\ *Corresponding author
}

\section{A B S T R A C T}

\section{Keywords}

Aegiceras

corniculatum,

Mangrove, Shoots,

Micropropagation,

in vitro, $\mathrm{BAP}$,

Kinetin and NAA

Article Info

Accepted:

22 October 2020

Available Online:

10 November 2020
The micropropagation protocol of tropical, small evergreen, true mangrove, and woody shrub or tree species, Aegiceras corniculatum, has been standardized. Axillary shoot proliferation was induced in vitro from nodal explants excised from 3-4 years field-grown old plant which was then used as explants for the establishment of in vitro cultures. Surface-sterilized explants were cultured on the Murashige and Skoog (MS) basal medium supplemented with different concentrations and a combination of growth regulators. Nodal explants, collected during January-March, exhibited $63 \%$ shoot proliferation and $1.799 \pm$ 0.013 number of shoots per explants when cultured on Murashige and Skoog (MS) basal medium supplemented with 6-benzylaminopurine (BAP) alone at $2.0 \mathrm{mg} / \mathrm{l}$. The maximum shoot proliferation $(75 \%)$ and the number of shoots per explants $(1.933 \pm 0.011)$ were recorded on the medium containing $3.0 \mathrm{mg} / \mathrm{l} \mathrm{BAP,} 0.5 \mathrm{mg} / \mathrm{l} \mathrm{Kinetin}(\mathrm{Kn})$, and $150 \mathrm{mg} / \mathrm{l}$ Ascorbic acid (as an antioxidant) which helped to reduce browning of the explants and facilitated the induction of shoots. Harder shoot explants containing 1-2 nodes were found to be better explants as compared with soft apical and axillary shoots. This is the first report of shoot proliferation by in vitro propagation techniques using nodal segments of $A$. corniculatum.

\section{Introduction}

Aegiceras corniculatum L. (Blanco.) is a tropical, small evergreen, true mangrove, and woody shrub or tree species, that grow in the intertidal zone, belonging to the Myrsinaceae family, commonly known as river mangrove and Khalsi in Bengali. It is also known as a crypto viviparous species of mangrove and is one of the pioneer mangroves which can thrive in $3 \%$ salinity ${ }^{(6)}$ by secreting salt though its leaf glands ${ }^{(3)}$. Moreover, it is an important honey-producing mangrove species in the Sundarban of West Bengal and 
Bhitarkanika mangrove forests of Orissa. The species forms a potential source for highquality honey and bee-wax from its flower and the wood is used as firewood, fencing materials, cores and mud wall, etc. Siddiqi ${ }^{(19)}$ also stated that honey bees produce the best quality honey from the nectar of $A$. corniculatum. Its wood is used for fuel and charcoal production. Rahaman ${ }^{(14)}$ recorded that the height of the plant in Sundarban varies from $2 \mathrm{~m}$ to $4 \mathrm{~m}$ and individual trees can reach up to 6-7 $\mathrm{m}$, but usually much shorter. The bark is rough and dark grey or black. Mangrove and associated plants provide a wide domain for therapeutic application in recent years, most yet to be explored. The mangroves and their associated plants have various economic values and environmental functions ${ }^{(9)}$. Bandaranayake ${ }^{(4)}$ informed that extracts from mangrove plant and associates has been used worldwide for medicinal purposes and have been recorded around 349 metabolites which turn out to be a rich source of steroids, diterpenes, and triterpenes, saponius, flavonoids, alkaloids, and tannins. Banerjee et al. ${ }^{(5)}$ reported that the leaves of $A$. corniculatum are rich in flavonoids. Roome et al. ${ }^{(15,16)}$ recorded that, A. corniculatum extract has analgesic, antiarthritic and anti-inflammatory properties, whereas, leaf suspension of this species showed a moderate reduction in blood glucose ${ }^{(8)}$.

This species has great medicinal, economical and ecological values for which it was being exploited indiscriminately for a very long time and became a threatened species according to ICUN red list $2010^{(7)}$. Tissue culture is a very important technique and widely used technologies in the tree improvement program. Sharp ${ }^{(18)}$ reported that micropropagation may be useful for forest trees characterized by poor seed set, absence of uniform seed production, and seed prone to genetic damage or loss of viability during storage-features common in mangroves ${ }^{(17)}$. Many numbers of endangered and threatened species have been successfully regenerated using in vitro culture methods using nodal segments. Many researchers reported that mangrove species are recalcitrant to tissue culture studies ${ }^{(1,11)}$. During in vitro culture of mangrove plants frequently turn brown or black and eventually die shortly after inoculation $^{(2,10)}$, as it excretes high tannin and phenolic compounds. Though, in vitro propagation of $A$. corniculatum has not yet been done and maybe the best alternative method for propagating this species. With this background, an experiment was conducted to explore the possibility of in vitro shoot proliferation from nodal explants of Aegiceras corniculatum L. (Blanco.) for the development of a protocol for future work.

\section{Materials and Methods}

\section{Explant selection and surface sterilization}

Seedlings of $A$. corniculatum were collected from Sundarbans Mangrove forest of India and grown at the experimental garden of the Institute of Forest Productivity campus, Ranchi during the monsoon season of the year (since May-June, 2014), Fresh axillary shoots produced during January-March and November-December which served as the source of explants. Young juvenile and healthy shoots were excised from field-grown plants of A. corniculatum. Removed all the leaves and cut into convenient sizes $(3-4 \mathrm{~cm}$ long and 0.3-0.5 cm thick) each with 1-2 nodes was washed with running tap water for 30 minutes to remove adhering dust particles from the surface, then immersed in water containing 2-3 drops of surfactant solution (Tween-20) for 10 minutes followed by Cetrimide $0.1 \%$ for 5 minutes in gentle agitating condition and rinsed thoroughly. After that, treated with $0.1 \%(\mathrm{w} / \mathrm{v})$ fungicide (Bavistin) solution for 18-20 min and cleaned 
4-5 times with sterilized double-distilled water. These were then surface sterilized with $0.1 \%(\mathrm{w} / \mathrm{v}) \mathrm{HgCl}_{2}$ for 3-9 min and rinsed with autoclaved water 4-5 times and transfer to the culture medium.

\section{Media preparation and cultural conditions}

After surface sterilization, explants trimmed to $(2-3 \mathrm{~cm}$ size $)$ were immunized on Murashige and Skoog's (MS) ${ }^{(13)}$ basal medium augmented with several concentrations of cytokinin BA, Kn, and TDZ $(0.5-5.0 \mathrm{mg} / \mathrm{l})$ alone and in combination with different concentrations of auxins NAA (0.5$2.0 \mathrm{mg} / \mathrm{l}$ ) with additives (ascorbic acid 150 $\mathrm{mg} / \mathrm{l})$ together with $3 \%(\mathrm{w} / \mathrm{v})$ sucrose and solidified with $0.8 \%(\mathrm{w} / \mathrm{v})$ agar were used for the shoot initiation. The final $\mathrm{pH}$ of the medium along with the Plant Growth Regulator (PGR) was adjusted to 5.6-5.8 using an electronic $\mathrm{pH}$ meter with the use of $0.1 \mathrm{~N} \mathrm{NaOH}$ or $0.1 \mathrm{~N} \mathrm{HCl}$ solutions. The media was dispensed about $25 \mathrm{ml}$ to each $25 \times 150 \mathrm{~mm}$ culture tube, capped with nonabsorbent cotton plug, and autoclaved for 15 min at $15 \mathrm{psi}$ at $121^{\circ} \mathrm{C}$. The culture was maintained at $25 \pm 2{ }^{\circ} \mathrm{C}$ under a 16-hour photoperiod.

\section{Bud break and shoot induction}

Aseptic transfer of explants was done in a laminar air-flow hood. The interior was swabbed with $70 \%$ ethanol before inoculation. After sterilization, explants were excised aseptically and inoculated on MS medium supplemented with various concentrations of cytokinin BA, Kn, and TDZ (0.5-5.0 $\mathrm{mg} / \mathrm{l})$ alone and in combination with different concentrations of auxins NAA (0.5$2.0 \mathrm{mg} / \mathrm{l}$ ) with additives (ascorbic acid 150 $\mathrm{mg} / \mathrm{l})$. The addition of auxins and cytokinins to the medium had a positive effect on shoot formation. Explants were evaluated in terms of percentage of shoot induction, the number of shoots per explants, shoot length, and the number of leaves per explants after 6 weeks of culture. Each treatment was replicated 3 times using 20 explants for each treatment.

\section{Statistical analysis}

Data recorded, were analysed using Systat-12 software ${ }^{(20)}$ for the computation of descriptive statistics (i.e., mean, standard deviation, and critical difference). The Completely Randomized Design (CRD) was followed for statistical analysis.

\section{Result and Discussion}

Plant tissue culture is an important tool not only for plant propagation and conservation but also it is used to enhance the plant bioactive compounds through cell culture ${ }^{(19)}$. This is the study mainly focused on developed a protocol for shoot proliferation of $A$. corniculatum through nodal explants using different concentrations of cytokinin (BA, Kin, and TDZ) alone and in combination with different concentrations of auxins (NAA) with additives (ascorbic acid $150 \mathrm{mg} / \mathrm{l}$ ). The results on the effect of different concentrations of cytokinin on in vitro establishment from nodal explants of $A$. corniculatum have been presented in (Table $1 \& 2$ ). Maximum shoot induction (63\%), number of shoots per explants $(1.799 \pm 0.013)$, shoot length (1.924 $\pm 0.043 \mathrm{~cm})$, and number of leaves per explant $(1.833 \pm 0.050)$ were recorded in media supplemented with BAP $2.0 \mathrm{mg} / \mathrm{l}$. In the case of media supplemented with Kinetin, $3.0 \mathrm{mg} / \mathrm{l}$ has induced maximum shoot induction $(42 \%)$ with the number of shoots per explants $(1.756 \pm 0.126)$, shoot length $(1.811 \pm 0.041 \mathrm{~cm})$, and the number of leaves per explants $(1.776 \pm 0.067 \mathrm{~cm})$. The maximum per cent of shoot induction in TDZ treatment was observed in TDZ $3.0 \mathrm{mg} / \mathrm{l}$ $(30 \%)$ with the number of shoots per explant $(1.571 \pm 0.038)$, shoot length $(1.477 \pm 0.030$ 
$\mathrm{cm})$, and the number of leaves per explants $(1.586 \pm 0.073 \mathrm{~cm})$. MS medium fortified with other additives had helped in the proliferation of the shoots, which might be due to the effect of cytokinin/auxins/antioxidants used either in alone or in combination. Similar in vitro propagation in other mangrove species have already been reported where shoot proliferation achieved on MS medium fortified with $0.13 \mu \mathrm{M}$ of $\boldsymbol{\alpha}$ - Naphthaleneacetic acid and $4.44 \mu \mathrm{M}$ of 6Benzylaminopurine from the mangrove species Candelilla $^{(12)}$. Species like Avicennia marine produced shoot in MS medium containing $0.01 \mathrm{mg} / \mathrm{lBA}, 2 \mathrm{mg} / \mathrm{l}$ kinetin, and $0.5 \mathrm{mg} / \mathrm{lBA}^{(1)}$.

Table.1 Effect of Cytokinin (BAP, Kn and TDZ) on shoot proliferation from nodal explant of Aegiceras corniculatum

\begin{tabular}{|c|c|c|c|c|c|c|}
\hline PGR & $\begin{array}{l}\text { Conc. } \\
\text { (mg/l) }\end{array}$ & $\begin{array}{l}\text { Treatmen } \\
\text { t code }\end{array}$ & $\begin{array}{c}\% \text { of } \\
\text { cultures } \\
\text { response }\end{array}$ & $\begin{array}{c}\text { Mean No of } \\
\text { shoots } \\
\text { /explant }\end{array}$ & $\begin{array}{l}\text { shoot length } \\
\text { in }(\mathrm{cm})\end{array}$ & $\begin{array}{c}\text { Mean No of } \\
\text { leaves/expl } \\
\text { ant }\end{array}$ \\
\hline Control & 0 & BKN1 & 10 & $1.244 \pm 0.244$ & $1.139 \pm 0.139$ & $1.244 \pm 0.244$ \\
\hline \multirow{6}{*}{ BAP } & 0.5 & BKN2 & 30 & $1.596 \pm 0.032$ & $1.474 \pm 0.077$ & $1.716 \pm 0.056$ \\
\hline & 1.0 & BKN3 & 60 & $1.763 \pm 0.091$ & $1.788 \pm 0.023$ & $1.767 \pm 0.107$ \\
\hline & 2.0 & BKN4 & 63 & $1.799 \pm 0.013$ & $1.924 \pm 0.043$ & $1.833 \pm 0.050$ \\
\hline & 3.0 & BKN5 & 52 & $1.724 \pm 0.043$ & $1.833 \pm 0.060$ & $1.733 \pm 0.035$ \\
\hline & 4.0 & BKN6 & 38 & $1.509 \pm 0.057$ & $1.474 \pm 0.057$ & $1.728 \pm 0.030$ \\
\hline & 5.0 & BKN7 & 28 & $1.509 \pm 0.064$ & $1.440 \pm 0.110$ & $1.617 \pm 0.022$ \\
\hline \multirow{6}{*}{$\mathbf{K N}$} & 0.5 & BKN8 & 20 & $1.648 \pm 0.044$ & $1.526 \pm 0.102$ & $1.589 \pm 0.038$ \\
\hline & 1.0 & BKN9 & 25 & $1.551 \pm 0.137$ & $1.387 \pm 0.030$ & $1.610 \pm 0.044$ \\
\hline & 2.0 & BKN10 & 35 & $1.558 \pm 0.093$ & $1.605 \pm 0.114$ & $1.663 \pm 0.059$ \\
\hline & 3.0 & BKN11 & 42 & $1.756 \pm 0.126$ & $1.811 \pm 0.041$ & $1.776 \pm 0.067$ \\
\hline & 4.0 & BKN12 & 38 & $1.506 \pm 0.046$ & $1.650 \pm 0.167$ & $1.686 \pm 0.079$ \\
\hline & 5.0 & BKN13 & 15 & $1.489 \pm 0.037$ & $1.436 \pm 0.127$ & $1.524 \pm 0.063$ \\
\hline \multirow{6}{*}{ TDZ } & 0.5 & BKN14 & 10 & $1.332 \pm 0.173$ & $1.293 \pm 0.034$ & $1.438 \pm 0.223$ \\
\hline & 1.0 & BKN15 & 20 & $1.414 \pm 0.000$ & $1.293 \pm 0.034$ & $1.525 \pm 0.056$ \\
\hline & 2.0 & BKN16 & 27 & $1.542 \pm 0.066$ & $1.353 \pm 0.064$ & $1.542 \pm 0.066$ \\
\hline & 3.0 & BKN17 & 30 & $1.571 \pm 0.038$ & $1.477 \pm 0.030$ & $1.586 \pm 0.073$ \\
\hline & 4.0 & BKN18 & 25 & $1.414 \pm 0.000$ & $1.259 \pm 0.034$ & $1.414 \pm 0.000$ \\
\hline & 5.0 & BKN19 & 10 & $1.382 \pm 0.212$ & $1.293 \pm 0.034$ & $1.276 \pm 0.138$ \\
\hline \multicolumn{4}{|r|}{ S.E. $( \pm m)$} & 0.105 & 0.081 & 0.098 \\
\hline \multicolumn{4}{|r|}{ C.D. $5 \%$} & 0.300 & 0.234 & 0.282 \\
\hline \multicolumn{4}{|r|}{ C.V. (\%) } & 11.734 & 9.426 & 10.652 \\
\hline
\end{tabular}

$*$ The figures in parentheses are square root transformed values. Data are shown as mean values of variables \pm SE. 
Table.2 Effect of cytokinin and auxin on the induction of shoot development in Aegiceras corniculatum from nodal segment

\begin{tabular}{|c|c|c|c|c|c|}
\hline Hormone con. (mg/l) & $\begin{array}{l}\text { Treatment } \\
\text { code }\end{array}$ & $\begin{array}{c}\% \text { of cultures } \\
\text { response }\end{array}$ & $\begin{array}{l}\text { No. of shoots } \\
\text { /explant }\end{array}$ & $\begin{array}{l}\text { Shoot length } \\
\text { in }(\mathrm{cm})\end{array}$ & $\begin{array}{c}\text { No. of } \\
\text { leaves/explant }\end{array}$ \\
\hline control & BKN1 & 10 & $1.138 \pm 0.138$ & $1.109 \pm 0.109$ & $1.000 \pm 0.000$ \\
\hline BAP 1.0 + KIN 0.5 & BKN2 & 30 & $1.443 \pm 0.029$ & $1.293 \pm 0.034$ & $1.414 \pm 0.000$ \\
\hline BAP $2.0+$ KIN 0.5 & BKN3 & 50 & $1.709 \pm 0.106$ & $1.639 \pm 0.069$ & $1.549 \pm 0.095$ \\
\hline BAP 3.0 + KIN 0.5 & BKN4 & 70 & $1.883 \pm 0.037$ & $1.905 \pm 0.048$ & $1.859 \pm 0.024$ \\
\hline BAP 4.0 + KIN 0.5 & BKN5 & 42 & $1.452 \pm 0.037$ & $1.446 \pm 0.078$ & $1.524 \pm 0.063$ \\
\hline BAP 1.0 + KIN 3.0 & BKN6 & 32 & $1.524 \pm 0.063$ & $1.592 \pm 0.002$ & $1.648 \pm 0.018$ \\
\hline BAP 2.0 + KIN 3.0 & BKN7 & 35 & $1.596 \pm 0.049$ & $1.639 \pm 0.069$ & $1.569 \pm 0.032$ \\
\hline BAP 3.0 + KIN 3.0 & BKN8 & 32 & $1.470 \pm 0.056$ & $1.470 \pm 0.101$ & $1.480 \pm 0.034$ \\
\hline BAP 4.0 + KIN 3.0 & BKN9 & 20 & $1.138 \pm 0.138$ & $1.109 \pm 0.109$ & $1.470 \pm 0.056$ \\
\hline BAP 1.0 + KIN 4.0 & BKN10 & 30 & $1.276 \pm 0.138$ & $1.248 \pm 0.127$ & $1.545 \pm 0.018$ \\
\hline BAP 2.0 + KIN 4.0 & BKN11 & 20 & $1.138 \pm 0.138$ & $1.109 \pm 0.109$ & $1.452 \pm 0.037$ \\
\hline BAP 3.0 + KIN 4.0 & BKN12 & 20 & $1.138 \pm 0.138$ & $1.075 \pm 0.075$ & $1.138 \pm 0.138$ \\
\hline BAP 4.0 + KIN 4.0 & BKN13 & 10 & $1.138 \pm 0.138$ & $1.138 \pm 0.138$ & $1.138 \pm 0.138$ \\
\hline BAP 1.0 + NAA 0.5 & BKN14 & 40 & $1.563 \pm 0.018$ & $1.666 \pm 0.042$ & $1.507 \pm 0.049$ \\
\hline BAP 2.0 + NAA 0.5 & BKN15 & 50 & $1.661 \pm 0.018$ & $1.739 \pm 0.071$ & $1.569 \pm 0.056$ \\
\hline BAP 3.0 + NAA 0.5 & BKN16 & 70 & $1.710 \pm 0.059$ & $1.880 \pm 0.039$ & $1.704 \pm 0.032$ \\
\hline BAP 4.0 + NAA 0.5 & BKN17 & 41 & $1.540 \pm 0.049$ & $1.504 \pm 0.049$ & $1.515 \pm 0.063$ \\
\hline BAP 1.0 + NAA 1.0 & BKN18 & 45 & $1.590 \pm 0.032$ & $1.477 \pm 0.030$ & $1.491 \pm 0.040$ \\
\hline BAP 2.0 + NAA 1.0 & BKN19 & 65 & $1.736 \pm 0.037$ & $1.809 \pm 0.072$ & $1.823 \pm 0.092$ \\
\hline BAP 3.0 + NAA 1.0 & BKN20 & 75 & $1.933 \pm 0.011$ & $2.036 \pm 0.031$ & $1.949 \pm 0.034$ \\
\hline BAP 4.0 + NAA 1.0 & BKN21 & 52 & $1.580 \pm 0.030$ & $1.756 \pm 0.102$ & $1.604 \pm 0.012$ \\
\hline BAP 1.0 + NAA 2.0 & BKN22 & 38 & $1.542 \pm 0.066$ & $1.764 \pm 0.023$ & $1.493 \pm 0.040$ \\
\hline BAP 2.0 + NAA 2.0 & BKN23 & 45 & $1.570 \pm 0.023$ & $1.786 \pm 0.064$ & $1.512 \pm 0.057$ \\
\hline BAP 3.0 + NAA 2.0 & BKN24 & 48 & $1.637 \pm 0.053$ & $1.417 \pm 0.052$ & $1.538 \pm 0.007$ \\
\hline \multirow[t]{4}{*}{ BAP 4.0 + NAA 2.0} & BKN25 & 30 & $1.470 \pm 0.056$ & $1.357 \pm 0.030$ & $1.623 \pm 0.023$ \\
\hline & & S.E. $(\underline{ \pm})$ & 0.080 & 0.075 & 0.059 \\
\hline & & C.D. $5 \%$ & 0.227 & 0.215 & 0.167 \\
\hline & & C.V. (\%) & 9.201 & 8.605 & 6.670 \\
\hline
\end{tabular}

*The figures in parentheses are square root transformed values. Data are shown as mean values of variables \pm SE. 


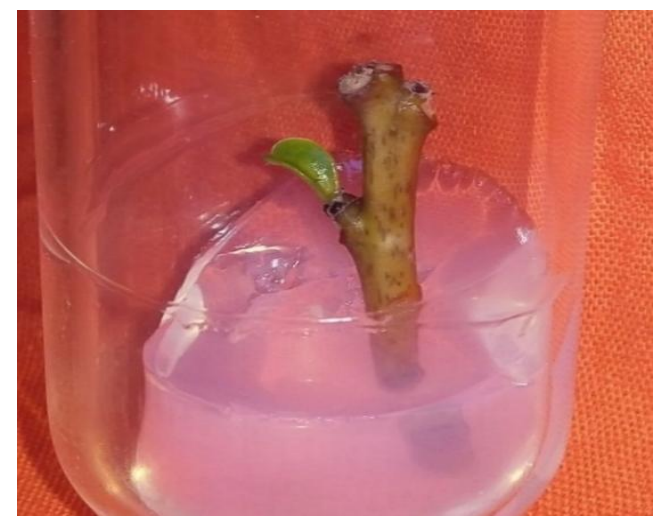

Fig.1 Shoot induction from nodal segment of $A$. corniculatum

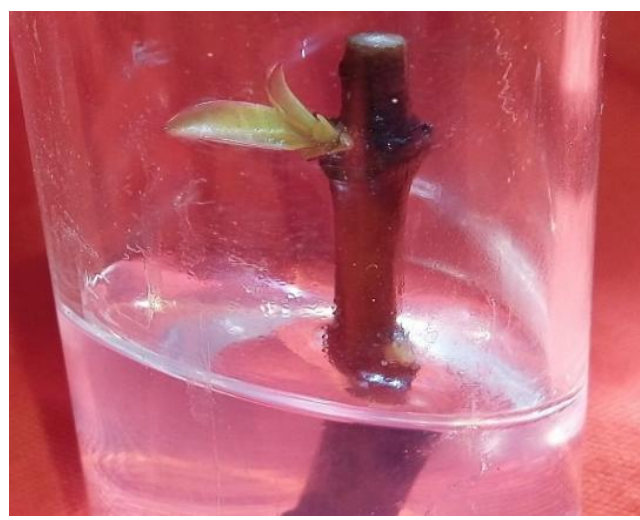

Fig.2 Shoot development from nodal segment of A. corniculatum
In another experiment, after surface sterilization, the nodal explants $(2-3 \mathrm{~cm}$ size $)$ were immunized on MS basal medium supplemented with various concentrations of cytokinin (BAP and $\mathrm{Kn}$ ) in combination with different concentrations of auxin (i.e., NAA) along with additives (i.e., ascorbic acid 150 $\mathrm{mg} / \mathrm{l})$. The results on the effect of different concentrations and combinations of cytokinin and auxins on in vitro establishment (Fig. $1 \&$ 2 ), from nodal explants of A. corniculatum, have been presented in Table 2. Maximum shoot induction $(75 \%)$, number of shoots per explants $(1.933 \pm 0.011)$, shoot length (2.036 $\pm 0.031 \mathrm{~cm})$ and number of leaves per explants $(1.949 \pm 0.034)$ were recorded on the medium of BKN20 (i.e., BAP $3.0 \mathrm{mg} / \mathrm{l}+\mathrm{Kn}$ $0.5 \mathrm{mg} / \mathrm{l}$ +Ascorbic acid $150 \mathrm{mg} / \mathrm{l})$. Comparatively harder shoot explants containing 1-2 nodes were found to be better explants as compared with soft apical and axillary shoots. This is the first tissue culture report on this species Aegiceras corniculatum.

In conclusion, the present study was proposed to develop a standard protocol for shoot proliferation from nodal explants followed by standardization of media and concentration and combinations of plant growth regulator for Aegiceras corniculatum. The shoots were proliferated from nodal explants when inoculated on MS medium supplemented with a combination of growth regulators i.e., 3.0 $\mathrm{mg} / \mathrm{l}$ of BAP and $1.0 \mathrm{mg} / \mathrm{l}$ of NAA. It is recommended to select harder shoot explants of A. corniculatum containing 1-2 nodes for better results under in vitro.

\section{References}

1. Al-Bahrany A, Al-Khayri JM. Micropropagation of grey mangrove Avicennia marina. Plant Cell, Tissue and Organ Culture. 2003; 72:87-93.

2. Arumugam $\mathrm{M}$, Panneerselvam $\mathrm{R}$. Micropropagation and phenolic exudation protocol for Excoecaria agallocha- an important mangrove. Asian Pacific Journal of Tropical Biomedicine. 2012; 2(2): S1096-S1101.

3. Ball, M.C. 1988. Salinity tolerance in the mangroves Aegiceras corniculatum and Avicennia marina. I. Water use in relation to growth, carbon partitioning, and salt balance. Functional Plant Biology, 15(3): 447-464.

4. Bandaranayake, W.M. 2002. Bioactivities, bioactive compounds and chemical constituents of mangrove plants. Wetlands Ecology and Management, 10(6): 421-452.

5. Banerjee, D., Chakrabarti, S., Hazra, A.K., Banerjee, S., Ray, J. and Mukherjee, B. 2008. Antioxidant activity and total phenolics of some mangroves in Sundarbans. African Journal of 
Biotechnology, 7(6): 75-79

6. Duke, N., Ball, M. and Ellison, J., 1998. Factors influencing biodiversity and distributional gradients in mangroves. Global Ecology \& Biogeography Letters, 7(1), pp.27-47.

7. Ellison, J., Koedam, N.E., Wang, Y., Primavera, J., JinEong, O., Wan-Hong Yong, J. \& Ngoc Nam, V. 2010. Aegiceras corniculatum. The IUCN Red List of Threatened Species 2010: e.T178797A7608891. DOI:10.2305/IUCN. UK.2010-2.RLTS.T178797A7608 891.en

8. Gurudeeban, S. Satyavani, K. Ramanathan, T. and Balasubramanian, T. 2012. Antidiabetic effect of a black mangrove species Aegiceras corniculatum in alloxaninduced diabetic rats. Journal of Advanced Pharmaceutical Technology and Research, 3(1): .52.

9. Kathiresan K, Qasim SZ. Biodiversity in mangrove ecosystems. Hindustan publishers, New Delhi, 2005, 251 pp (ISBN: 8170750792).

10. Kathiresan Kandasamy and Ravinder Singh Chinappan. 2013. Preliminary conservation effort on Rhizophora annamalayana Kathir. The only endemic mangrove to India through In vitro method. J. plant Develop 20:1-5.

11. Kawana Y, Sasamoto H. Stimulation effects of salts on growth in suspension culture of a mangrove plant, Sonneratia alba, compared with another mangrove, Bruguiera sexangula and non-mangrove tobacco BY-2 cells. Plant Biotechnology, 2008; 25:151-155.

12. Jakobek, J.L. Backhans, R.A. Herman, K. 1986. Micropropagation of Candelis, Euphorbia antisyphilitica zucc. Plant Cell, Tissue and Organ culture, 7: 145-148.
13. Murashige, T. Skoog, F., 1962. A revised medium for rapid growth and bioassays with tobacco tissue cultures. Physical Plant 15:473-497.

14. Rahman, M.M., 2016. Development of nursery and plantation techniques of Aegiceras corniculatum (L.) Blanto and its site suitability in the Sundarban of Bangladesh. Bangladesh Res. Pub. J, 12(1), pp.50-59.

15. Roome, T. Dar, A. Naqvi, S. and Choudhary, M.I. 2011. Evaluation of antinociceptive effect of Aegiceras corniculatum stems extracts and its possible mechanism of action in rodents. Journal of ethnopharmacology, 135(2): 351-358.

16. Roome, T. Razzak, A. Ali, P. Aziz, S. Dar, A. Naqvi, S. and Choudhary, M.I. 2014. Therapeutic Effect of Aegiceras corniculatum in Chronic Granulomatous Inflammation and Arthritis. Journal of the Dow University of Health Sciences (JDUHS), 8(3).

17. Saenger P. Morphological, anatomical and reproductive adaptions of Australian mangroves. In: Mangrove ecosystems in Australia (Eds. B.F. Clough), Australian National University Press, Canberra, Australia, 1982, 153-191.

18. Sharp WR, Sondahl MR, Caldas LS, Maraffa, SB. In: Horticultural Reviews. Vol. 2. (Eds. Janick J.). AVI Publishing Co, Westport, Conn, USA, 1980, 1-268.

19. Siddiqi, N.A. 2001. Mangrove forestry in Bangladesh. Institute of Forestry \& Environmental Sciences, University of Chittagong, Chittagong, Bangladesh.

20. Wilkinson L, Coward M. SYSTAT: Statistics-II (Version 12). Systat Software Inc., Sanjose, CA-95110, 2007.

\section{How to cite this article:}

Rajneesh Kumar, Animesh Sinha, Pradip Kumar Sarkar and Jai Kumar. 2020. In vitro Shoot Proliferation from Nodal Explants of Aegiceras corniculatum L. (Blanco.). Int.J.Curr.Microbiol.App.Sci. 9(11): 3113-3119. doi: https://doi.org/10.20546/ijcmas.2020.911.375 